\title{
The Experimental Study on Depletion Development Factors of Condensate Gas Reservoirs
}

\author{
Guolong Zhang \\ Chongqing University of Science and Technology \\ Chongqing, China \\ 820564951@qq.com
}

Zhiqiang He

Southwest Oil and Gas Field Branch, CNPC, China

yrzg1@.163.com

Jianjun Zhu

Chongqing University of Science and Technology

Chongqing, China

419296387@qq.com

\author{
Qingheng Zeng \\ Chongqing University of Science and Technology \\ Chongqing, China \\ 1127197118@qq.com \\ Pengjiu Wang \\ Chongqing University of Science and Technology \\ Chongqing, China \\ 343622094@qq.com
}

\begin{abstract}
There will be a variety of factors restricting the development of the condensate gas reservoirs in the process of mining depletion. There are many important implications for the actual production to study the results of these factors of recovery ratio. Taking advantage of the high temperature high pressure full diameter core flooding system, this paper conducts a lab experiment of the victory, the irreducible water saturation, the reservoir and the fluid properties to obtain the results of its impact on recovery ratio. The experiment results show that under the influence of these four factors, condensate ratio has varying degrees of change, and the gas ratio will not be much fluctuation.
\end{abstract}

Keywords-Condensate Gas Reservoirs; Recovery Ratio; Factor; Experiment

\section{INTRODUCTION}

Recently, the development of condensate gas reservoirs plays an increasingly important role in the development of various types of gas reservoirs [1,2]. The depletion development is one of the most popular ways to develop condensate gas reservoirs because of its low cost and high earnings. In the course of depletion development, the gas in the formation will retrograde condensation when the local level pressure is less than the dew point pressure $[3,4]$. The condensate cannot flow before the saturation reaches the critical flow saturation and become the critical factor to reduce the output $[5,6]$. When the pressure reduces fatherly, there will be more and more condensates especially near wellbore. People can develop the condensate when reach the critical flow saturation to get added value $[7,8]$. This article conducts a lab experiment to study four factors that can influence oil and gas recovery and the results have some significance to the block selection and the production rate.

\section{THE METHOD OF THE EXPERIMENT}

\section{A. The Experiment Device}

Experiments involved in this article use of high temperature and pressure full diameter core flooding system, Fig. 1 is its structure and process. The key part of the device is full diameter core holder, includes the outer cylinder, rubber sleeve and axial connector. Particularly, the depletion speed in the core controlled by the pressure drop rate in the exit.

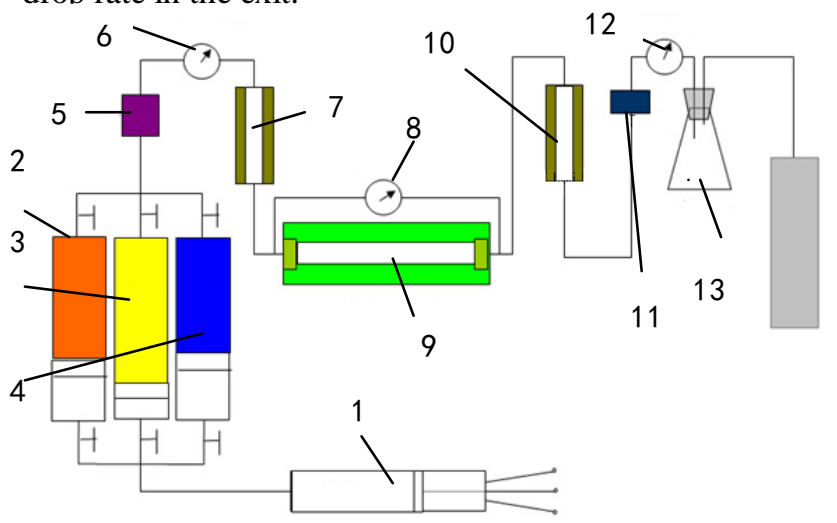

Figure 1. The structure and process of high temperature and pressure full diameter core flooding system 1- Injection pump 2-oil 3-gas 4-water 5- Filter 6- Injection pressure gauge 7- Entrance observation window 8- Differential pressure gauge 9- Long core holder 10- Outlet viewing window 11- Back pressure regulator 12- Back pressure gauge 13- Splitter 


\section{B. Experimental Content}

1) Sample preparation

\section{a) Fluids}

Condensate is density $80 \mathrm{~g} / \mathrm{m} 3,150 \mathrm{~g} / \mathrm{m} 3,250 \mathrm{~g} / \mathrm{m} 3$ condensate and the dew point pressure is $30 \mathrm{MPa}$.

\section{b) Cores}

The cores used in the experiment are natural whole cores. The cores numbered 2 are outcrop cores and numbered Y-3 are reservoir core. researchers can see its basic physical parameters after grind, wash and dry in the TABLE I.

TABLE I. THE BASIC PHYSICAL PARAMETERS OF THE WHOLE CORES

\begin{tabular}{|c|c|c|c|c|}
\hline Number & $\begin{array}{c}\text { Length } \\
\boldsymbol{c m}\end{array}$ & $\begin{array}{c}\text { Diameter } \\
\boldsymbol{c m}\end{array}$ & $\begin{array}{c}\text { Porosity } \\
\boldsymbol{\%}\end{array}$ & $\begin{array}{c}\text { Permeability } \\
\boldsymbol{m D}\end{array}$ \\
\hline 2 & 10.162 & 6.551 & 8.96 & 4.29 \\
\hline Y-3 & 10.168 & 6.483 & 9.48 & 1.19 \\
\hline
\end{tabular}

2) Experiment program

The experiment simulates the formation temperature $78{ }^{\circ} \mathrm{C}$ and formation pressure $34 \mathrm{MPa}$, holding one variable parameter every time, study the different victory, the different irreducible water saturation, the different reservoir and the different fluid properties how to influence recovery ratio.

(1) Fully saturated two Y-3 cores with distilled water and establish irreducible water saturation of $48 \%$ with nitrogen. Then test condensate gas system which condensate density $150 \mathrm{~g} / \mathrm{m} 3$ at different exhaustion speeds used core flooding devices.

(2) Fully saturated two Y-3 cores with distilled water and establish irreducible water saturation of $48 \%$ and $28 \%$ with nitrogen. Experiment and keep the condensate content and exhaustion speed same.

(3) Exhaustion experiment uses the condensate gas system with condensate density $250 \mathrm{~g} / \mathrm{m} 3$. Keep the cores that have different permeability and the same exhaustion speed and irreducible water saturation.

(4) Exhaustion experiment uses the condensate gas system with different condensate density $(80 \mathrm{~g} / \mathrm{m} 3$, $150 \mathrm{~g} / \mathrm{m} 3$ and $250 \mathrm{~g} / \mathrm{m} 3$ ) and keeps the same core properties, exhaustion speed and water saturation.

\section{III.THE EXPERIMENTAL RESULTS AND ANALYSIS}

The Exhaustion Speed

We can see the experiment results under the different exhaustion speeds in the TABLE II and Fig. 2. The exhaustion speed faster, the higher condensate recovery ratio. Because the oil equilibrium will be varied along with a change in an equilibrium condition, but the course isn't instantaneous. Since the speed is so fast, the condensate will be taken out with the gas together before it precipitates completely.
The experimental fluid samples using oil sample from splitter and nature gas, prepared under the condition of the

TABLE II. THE DIFFERENT RECOVERY RATIOS UNDER THE DIFFERENT EXHAUSTION SPEEDS (CONDENSATE DENSITY 150G/M3)

\begin{tabular}{|c|c|c|c|}
\hline Core & $\begin{array}{c}\text { Exhaustion } \\
\text { Speed }\end{array}$ & $\begin{array}{c}\text { Condensate } \\
\text { Recovery } \\
\text { Ratio, \% }\end{array}$ & $\begin{array}{c}\text { Condensate Gas } \\
\text { Recovery } \\
\text { Ratio,\% }\end{array}$ \\
\hline $\mathrm{Y}-3$ & $2 \mathrm{MPa} / \mathrm{h}$ & 31.06 & 83.43 \\
\hline $\mathrm{Y}-3$ & $1 \mathrm{MPa} / \mathrm{h}$ & 30.46 & 84.54 \\
\hline
\end{tabular}
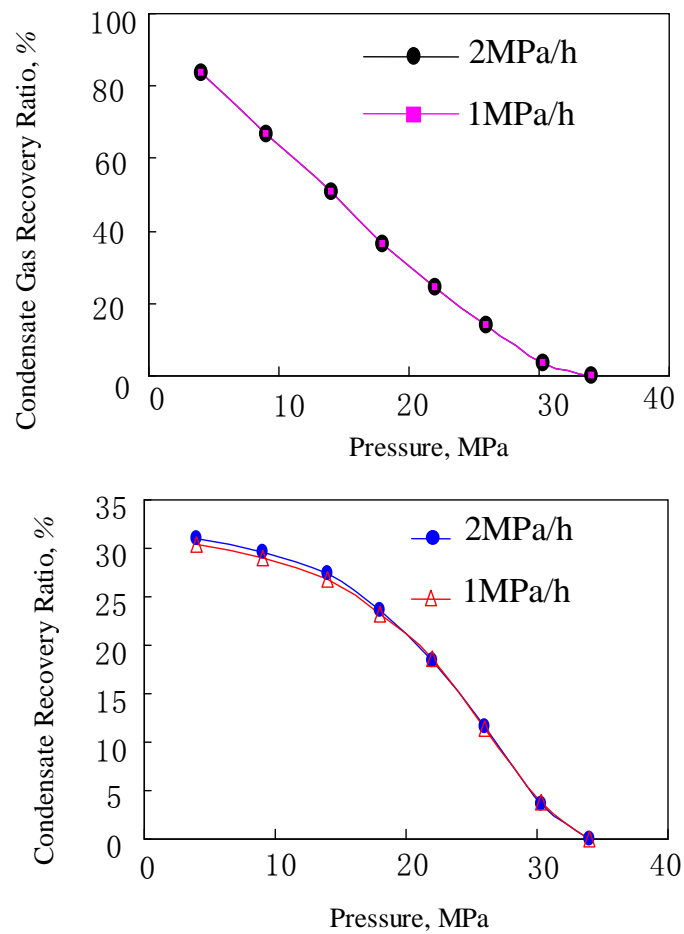

Figure 2. Comparison curves of different exhaustion speeds ( condensate density $150 \mathrm{~g} / \mathrm{m} 3$ )

\section{The Irreducible Water Saturation}

Researchers can see the experiment results under the different water saturations in the Table III and Fig. 3. It imply that the water saturation play a minor role in inflecting the recovery ratio. This is because most reservoirs are mainly wet ability, the micro pore mainly occupied by water phase. When there are higher water saturation constraints, a large number of tiny pores are occupied by water, oil and gas mainly flows in large pores. But if the irreducible water saturation is small, the condensate is difficult to be taken out because of the adsorption inside porous medium and capillary force.

TABLE III. THE DIFFERENT RECOVERY RATIOS UNDER THE DIFFERENT WATER SATURATIONS (CONDENSATE DENSITY 150G/M3 )

\begin{tabular}{|c|c|c|c|}
\hline core & $\begin{array}{c}\text { water } \\
\text { saturation }\end{array}$ & $\begin{array}{c}\text { condensate recovery } \\
\text { ratio, } \%\end{array}$ & $\begin{array}{c}\text { Condensate gas } \\
\text { recovery ratio, } \%\end{array}$ \\
\hline Y-3 & $48 \%$ & 31.06 & 83.43 \\
\hline Y-3 & $28 \%$ & 29.56 & 84.58 \\
\hline
\end{tabular}



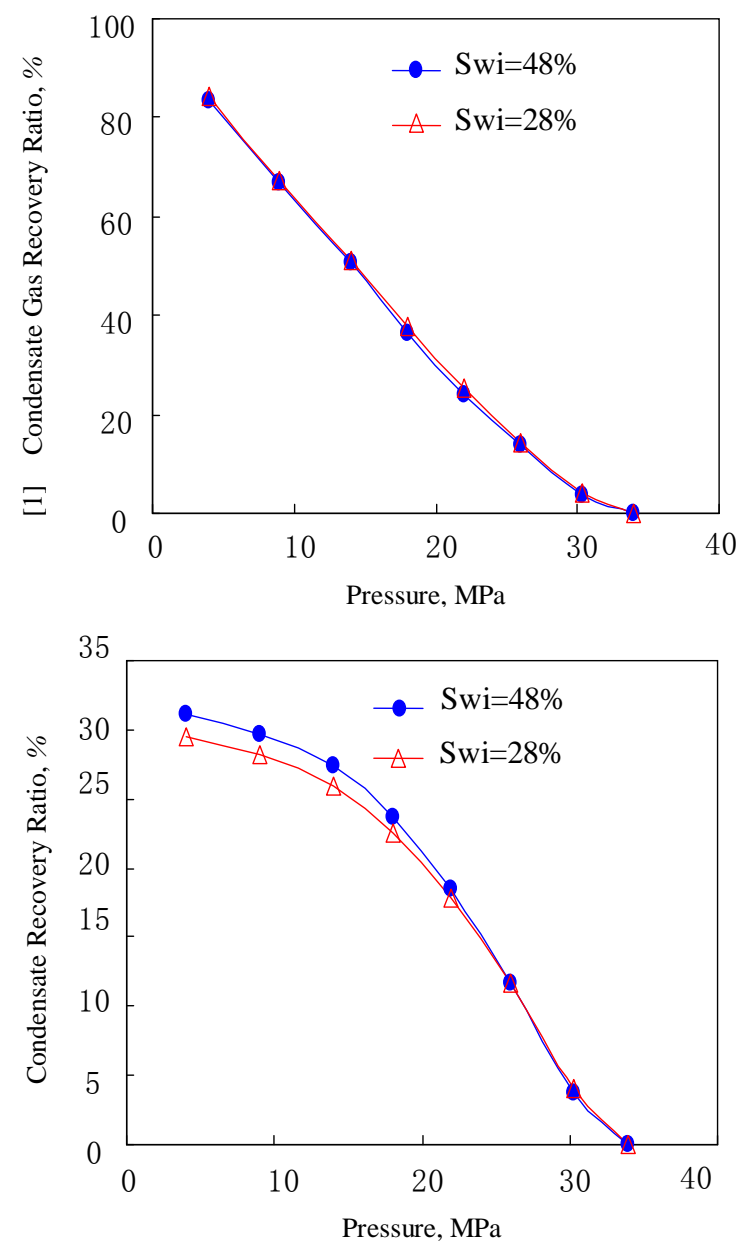

Figure 3. Comparison curves of different water saturations (Condensate density $150 \mathrm{~g} / \mathrm{m}^{3}$ )

\section{The Reservior Properties}

Researchers can see the experiment results under the different reservoir properties in the TABLE IV and Fig. 4. Though the condensate recovery ratio of 2 is taller than $\mathrm{Y}-35.26 \%$, the condensate gas recovery ratio is almost consistency. This is because the better material reservoir and fluid flow condition, the oil phase flows more easily, but has little effect on the gas. Equations

TABLE IV. THE DIFFERENT RECOVERY RATIOS UNDER THE DIFFERENT RESERVOIR RROPERTIES (CONDENSATE DENSITY 250G/M3)

\begin{tabular}{|c|c|c|c|c|}
\hline Core & $\begin{array}{c}\text { Porosity, } \\
\%\end{array}$ & $\begin{array}{c}\text { Permeability } \\
, \mathrm{mD}\end{array}$ & $\begin{array}{c}\text { condensa } \\
\text { te } \\
\text { recovery } \\
\text { ratio, } \%\end{array}$ & $\begin{array}{c}\text { Condensate gas } \\
\text { recovery } \\
\text { ratio, \% }\end{array}$ \\
\hline $\mathrm{Y}-3$ & 9.48 & 1.19 & 33.38 & 84.64 \\
\hline 2 & 13.42 & 4.29 & 38.64 & 84.29 \\
\hline
\end{tabular}
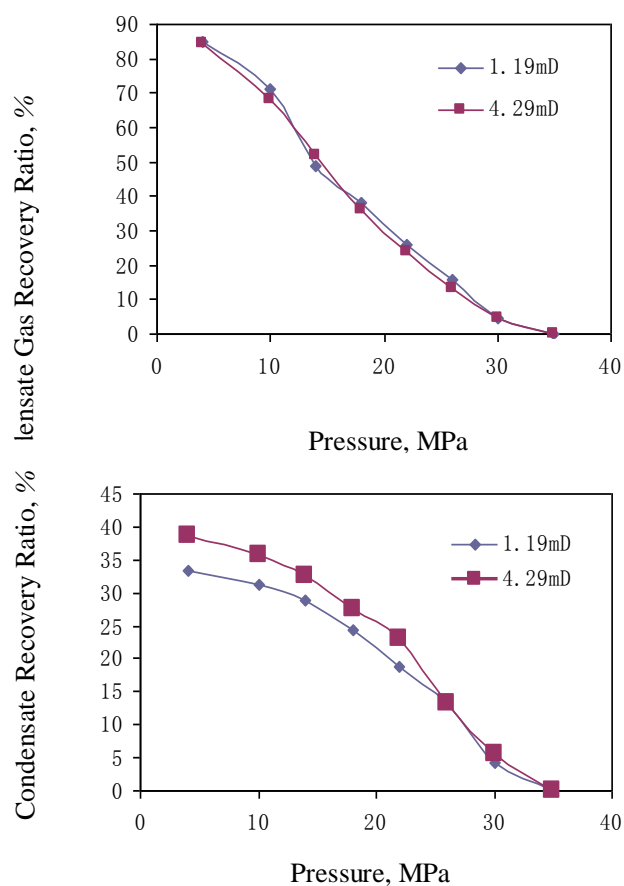

Figure 4. Comparison curves of different reservoir properties (condensate density $250 \mathrm{~g} / \mathrm{m} 3$ )

\section{E. The Fluid Properties}

Generally speaking, the different effect of fluid properties has a greater impact on the exploitation result. Compared the results under the different fluid properties(TABLE V and Fig. 5), researchers found that the condensate in the gas system of condensate density $250 \mathrm{~g} / \mathrm{m} 3$ is easily to get the critical flow state. Therefore, the condensate recovery ratio is higher.

TABLE V. THE DIFFERENT RECOVERY RATIOS UNDER THE DIFFERENT FLUID PROPERTIES

\begin{tabular}{|c|c|c|c|}
\hline $\begin{array}{c}\text { Condensate } \\
\text { Density }\left(\mathrm{g} / \mathrm{m}^{3}\right)\end{array}$ & $\begin{array}{c}\text { Condensate } \\
\text { Recovery } \\
\text { Ratio, } \%\end{array}$ & $\begin{array}{c}\text { Condensate } \\
\text { Gas Recovery } \\
\text { Ratio, } \%\end{array}$ & Remark \\
\hline 80 & 29.87 & 82.35 & $\begin{array}{c}\text { In the core, the } \\
\text { presser from } \\
\text { 30MPareduce } \\
\text { to 5MPa }\end{array}$ \\
\hline 150 & 31.06 & 83.41 & 84.64 \\
\hline
\end{tabular}

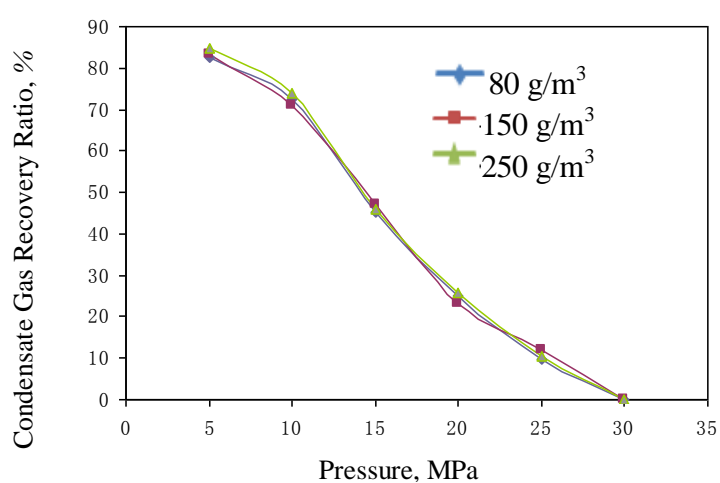




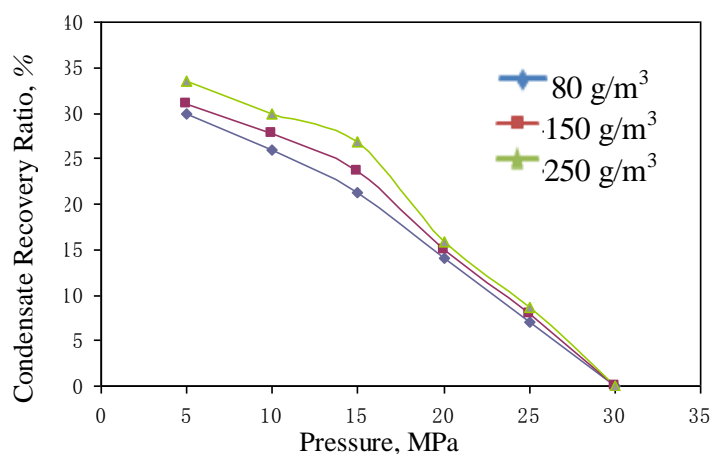

Figure 5. Comparison curves of different fluid properties

\section{CONCLUSIONS}

Test four factors that can influence the recovery ratio, study the effect of its impact. Totally, the exhaustion speed the irreducible water saturation, the reservoir properties and fluid properties will be different degrees of impact on condensate recovery ratio, but gas ratio change little.

(1)When the exhaustion speed changes, both the recovery will change little, it is not the main factors which influence the ultimate recovery. Therefore, the gas production rate impacts on the ultimate recovery are unlikely.

(2)The higher irreducible water saturation, the higher condensate recovery ratio, but the condensate gas recovery ratio. This is because the general to the wet ability of the main reservoir, the water phase will occupy only tiny pores formation. Oil from large pores can still flow. For the precipitated condensate get rid of the constraints from adsorption inside porous medium and capillary force, should try to choose a certain irreducible water saturation of condensate gas reservoir development using depletion.

(3)Reservoir properties is not the same, gas recovery does not substantially change much. In contrast, the better of the reservoir condition, the higher of the oil phase recovery. Because the oil phase will flow more easily if the reservoir condition is better. Therefore, the oil phase recovery will become higher as reservoir conditions changed for the better. Therefore, when select the block to use depletion develops, should try to choose large permeability, fracture is developed blocks.

(4) The higher density of condensate, the higher recovery ratio. This is because as the condensate content increased slowly and gradually reached the critical flow of condensate oil saturation. Therefore, researchers should try to choose the critical condensate saturation lower depletion blocks were developed, that the higher irreducible water saturation and better reservoir condition blocks.

\section{ACKNOWLEDGMENT}

We thank the Campus Scientific Research Fund (YKJCX2014010) of Chongqing University of Science and Technology. Researchers also thank Department of Petroleum Engineering at Chongqing University of Science and Technology for providing resources and computing facilities. Researchers gratefully acknowledge Dr. Zeng Qingheng for his contributions during this research.

\section{REFERENCES}

[1] Hu Yongquan, Zhu Juhui and Zhao Jinzhou etal. Effects of Hydrocarbon Components on ProductionPerformance in Condensates Gas Reservoirs[J]. Fault Block Oil \& Gas Field, 2004, 11( 5) : 34-36

[2] KALAYDJIAN F J, BOUYBIAUX B J, LOMBARD J-M. Predicting gas-condensate reservoir performance: how flow parameters are altered when approaching production wells $[\mathrm{J}]$. SPE 36715, 1996.

[3] Gao Jianjun,Han Jifan, Hao Wei etal. Study on evaluation and removal of retrograde condensate damage in Q iudong gas filed[J]. Special reservoir. 2010, 02:85-87.

[4] KEWEN LI, ABBAS FIROOZABADI. Phenomenological modeling of critical condensate saturation and relative perm abilities in gas/condensate systems [J]. SPE56014, 2000.

[5] Li Qian, Li Xiangfang, Shi Juntai etal. Development on critical condensate saturation in gas condensate reservoir[J]. Oil Drilling \& Production Technology. 2010, S1:36-41.

[6] XIULI WANG, MOHANTY K. Pore-network model of flow in gas/condensate reservoirs [J]. SPE 67857,2000.

[7] Yang Haitao, Wang Dong, Lv Jing etal. Experimental study on critical flow saturation in condensate gas reservoir development [J]. Oil Drilling \& Production Technology. 2010,S1:42-44

[8] FANG FANG.A Phenomenological modeling of critical condensate saturation $[\mathrm{J}]$. SPE 36716, 1996. 